\title{
Article \\ Nanostructure Engineering via Intramolecular Construction of Carbon Nitride as Efficient Photocatalyst for $\mathrm{CO}_{2}$ Reduction
}

\author{
Muhammad Sohail $^{1}{ }^{(D)}$, Tariq Altalhi ${ }^{2}$, Abdullah G. Al-Sehemi ${ }^{3}$, Taha Abdel Mohaymen Taha ${ }^{4,5}$, \\ Karam S. El-Nasser 6,7, Ahmed A. Al-Ghamdi ${ }^{8}$ (D), Mahnoor Boukhari ${ }^{9}$, Arkom Palamanit ${ }^{10}$, Asif Hayat ${ }^{11, * 1 D}$, \\ Mohammed A. Amin ${ }^{2, *}$ and Wan Izhan Nawawi Bin Wan Ismail 12,*
}

check for updates

Citation: Sohail, M.; Altalhi, T.; Al-Sehemi, A.G.; Taha, T.A.M.; S. El-Nasser, K.; Al-Ghamdi, A.A.; Boukhari, M.; Palamanit, A.; Hayat, A.; A. Amin, M.; et al. Nanostructure Engineering via Intramolecular Construction of Carbon Nitride as Efficient Photocatalyst for $\mathrm{CO}_{2}$ Reduction. Nanomaterials 2021, 11, 3245. https: / / doi.org/10.3390/ nano11123245

Academic Editor: Otakar Frank

Received: 16 October 2021

Accepted: 18 November 2021

Published: 29 November 2021

Publisher's Note: MDPI stays neutral with regard to jurisdictional claims in published maps and institutional affiliations.
1 Yangtze Delta Region Institute (Huzhou), University of Electronic Science and Technology of China, Huzhou 313001, China; sohailncp@gmail.com

2 Department of Chemistry, College of Science, Taif University, P.O. Box 11099, Taif 21944, Saudi Arabia; ta.altalhi@tu.edu.sa

3 Department of Chemistry, Faculty of Science, Research Center for Advanced Materials Science (RCAMS), King Khalid University, P.O. Box 9004, Abha 61413, Saudi Arabia; agsehemi@kku.edu.sa

4 Physics Department, College of Science, Jouf University, Sakaka 75471, Saudi Arabia; themaida@ju.edu.sa

5 Physics and Engineering Mathematics Department, Faculty of Electronic Engineering, Menoufia University, Menouf 32952, Egypt

6 Chemistry Department, College of Science and Arts, Jouf University, Al-Gurayyat 77447, Saudi Arabia; karamsaif@ju.edu.sa

7 Chemistry Department, Faculty of Science, Al-Azhar University, Assiut 71524, Egypt

8 Department of Physics, Faculty of Science, King Abdulaziz University, Jeddah 21589, Saudi Arabia; agamdi@kau.edu.sa

9 College of Material Science \& Engineering, Beijing University of Technology, Beijing 100081, China; bukharimahnoor11@gmail.com

10 Energy Technology Program, Department of Specialized Engineering, Faculty of Engineering, Prince of Songkla University, 15 Karnjanavanich Rd., Hat Yai, Songkhla 90110, Thailand; energy_man001@hotmail.com

11 State Key Laboratory of Photocatalysis on Energy and Environment, College of Chemistry, Fuzhou University, Fuzhou 350116, China

12 Faculty of Applied Sciences, Universiti Teknologi MARA, Cawangan Perlis, Arau Perlis 02600, Malaysia

* Correspondence: asifncp11@yahoo.com (A.H.); Mohamed@tu.edu.sa (M.A.A.); wi_nawawi@uitm.edu.my (W.I.N.B.W.I.)

Abstract: Light-driven heterogeneous photocatalysis has gained great significance for generating solar fuel; the challenging charge separation process and sluggish surface catalytic reactions significantly restrict the progress of solar energy conversion using a semiconductor photocatalyst. Herein, we propose a novel and feasible strategy to incorporate dihydroxy benzene (DHB) as a conjugated monomer within the framework of urea containing $\mathrm{CN}$ (CNU-DHBx) to tune the electronic conductivity and charge separation due to the aromaticity of the benzene ring, which acts as an electron-donating species. Systematic characterizations such as SPV, PL, XPS, DRS, and TRPL demonstrated that the incorporation of the $\mathrm{DHB}$ monomer greatly enhanced the photocatalytic $\mathrm{CO}_{2}$ reduction of $\mathrm{CN}$ due to the enhanced charge separation and modulation of the ionic mobility. The significantly enhanced photocatalytic activity of $\mathrm{CNU}_{-} \mathrm{DHB}_{15.0}$ in comparison with parental $\mathrm{CN}$ was $85 \mu \mathrm{mol} / \mathrm{h}$ for $\mathrm{CO}$ and $19.92 \mu \mathrm{mol} / \mathrm{h}$ of the $\mathrm{H}_{2}$ source. It can be attributed to the electron-hole pair separation and enhance the optical adsorption due to the presence of DHB. Furthermore, this remarkable modification affected the chemical composition, bandgap, and surface area, encouraging the controlled detachment of light-produced photons and making it the ideal choice for $\mathrm{CO}_{2}$ photoreduction. Our research findings potentially offer a solution for tuning complex charge separation and catalytic reactions in photocatalysis that could practically lead to the generation of artificial photocatalysts for efficient solar energy into chemical energy conversion.

Keywords: carbon nitride $(\mathrm{CN})$; dihydroxy benzene (DHB); photocatalysis; copolymerization; $\mathrm{CO}_{2}$ reduction 


\section{Introduction}

The production of renewable fuels with rich $\mathrm{CO}_{2}$ as raw materials through solar energy has been considered the best solution for energy crises and environmental remediations [1-5]. It is always attracting and has received much attention for generating renewable fuel from the conversion of $\mathrm{CO}_{2}$ through semiconductor-based photocatalysts [5-8]. To date, a variety of semiconductor photocatalysts including $\mathrm{CeO}_{2}, \mathrm{TiO}_{2}, \mathrm{Ga}_{2} \mathrm{O}_{3}, \mathrm{ZnO}, \mathrm{ZnGe}_{2} \mathrm{O}_{4}$, and $\mathrm{Bi}_{2} \mathrm{WO}_{6}$ have been used for the reduction of $\mathrm{CO}_{2}$ source [9-15]. Unfortunately, such semiconductor materials have a broad bandgap that absorbs only ultraviolet light irradiation and has less photocorrosion potential. Furthermore, bulk semiconductors typically have a high recombination rate of photoinduced charge carriers $[16,17]$. All of these disadvantages substantially jeopardize the effectiveness and successful long-term implications of $\mathrm{CO}_{2}$ photoconversion on the basis of photocatalysts. As a result, it is vital for photocatalytic $\mathrm{CO}_{2}$ conversion to fabricate and construct visible light-responsive, highly efficient, and durable catalysts $[5,18,19]$. Numerous strategies, such as morphological tailoring, junction creation, crystal facet engineering, and surface modification, can be used to prevent the recombination of highly reactive photogenerated carriers in photocatalysis. Despite this, the photocatalytic performance is limited due to a lack of active sites and photocorrosion features. The proper coupling of one semiconductor with other materials to form a heterojunction may aid in the separation of spatial charges and protect the light-harvesting semiconductor from photocorrosion [20-22].

Numerous articles have been published about heterogeneous photocatalysis since 1981, demonstrating the topic's increasing popularity [23]. The heterogeneous catalyst has a well-defined structure, and the reaction is multi-sited, involving multiple active sites such as edge, face, and defect simultaneously [24]. Photocatalytic materials such as metal oxides, sulfides, and nitrides have been studied in the literature widely [25]. CdS is a semiconductor with a bandgap of $2.42 \mathrm{eV}$ and an absorption peak of $514 \mathrm{~nm}$. Consequently, CdS is more effective at absorbing visible light or UV radiation with a wavelength of less than $514 \mathrm{~nm}$ [26]. Aside from water decomposition [26] and $\mathrm{CO}_{2}$ reduction [27], CdS semiconductors have a bandgap location that is ideal for several photocatalytic processes. Furthermore, the CdS conduction band edge is lower than the other common semiconductors (such as $\mathrm{TiO}_{2}, \mathrm{SrTiO}_{3}$, and $\mathrm{ZnO}$ [28]), which means that photoelectrons of $\mathrm{CdS}$ have a stronger reducing power in the photocatalytic reaction. As a result, the photocatalytic properties of CdS have been extensively studied. However, the CdS material is susceptible to light corrosion, which limits the number of photocatalysts that can be restored.

Carbon nitride $(\mathrm{CN})$ has received considerable attention as a metal-free organic semiconductor due to its remarkable thermal and chemical stability and favorable electrical structure [29-35]. CN has been shown to be a potential solar energy conversion candidate [36,37]. The synthesis of bulk $\mathrm{CN}$ by the direct co-condensation process limits their applications because of its low surface area and less active site [13,34,38-40]. To improve the quantum efficiency in the visible light region, the above-mentioned drawbacks must be overcome that limit the applications of $\mathrm{CN}[35,41]$. The fabrication of hierarchical micro/nanostructures is an effective method for addressing these issues. Micro/nanostructured $\mathrm{CN}$ was obtained using a variety of techniques, including hard templating, which was commonly used to obtain porous, sphere, and tubular carbon nitride (CN) [13,39]. However, the templating technique is expensive, time-intensive, and not eco-friendly, given the environmentally toxic reagents to be used for the extraction of the prototype, which prevents further functionalization. A variety of techniques have been used to modify $\mathrm{CN}$, including doping, morphology tailoring in the form of nanorods, and hollow nano-spheres junction fabrication, crystal facet engineering, and surface modification [5,42-44]. Inspired by these advancements, molecular engineering (copolymerization) has arisen as a new significant technique by incorporating new energetic organic conjugated monomers within the framework of $\mathrm{CN}$ to improve its photocatalytic properties $[5,33,37,39,43,44]$. Incorporating these organic motifs into the $\mathrm{CN}$ structure via copolymerization enhances photogenerated electron accumulation and transport, leading 
to improved photocatalytic activity under visible light irradiation [5,33,37]. To achieve high photocatalytic efficiency and stability, this copolymerization grafts organic motifs within the $\mathrm{CN}$ skeleton by using a simple one-step condensation technique [42]. From the perspective of this approach, Nie et. al. developed Z-scheme g- $\mathrm{C}_{3} \mathrm{~N}_{4} / \mathrm{ZnO}$ microspheres for $\mathrm{CO}_{2}$ reduction [45]. Hasija et al. designed Z-scheme g- $\mathrm{C}_{3} \mathrm{~N}_{4} / \mathrm{AgI} / \mathrm{ZnO} / \mathrm{CQDs}$ photocatalysts for the efficient photodegradation of 2,4-dinitrophenol, which exhibited remarkable stability and recyclability [21]. Hayat et al. examined the introduction of trimesic acid as a conjugated co-monomer within the $\mathrm{CN}$ framework that was highly effective in photocatalytic $\mathrm{CO}_{2}$ reduction $[5,18]$. Intramolecular conjugating monomers are of great interest and are discovered as energized candidates for intramolecular donor-acceptor behaviors within the triazine subunit of $\mathrm{CN}$ to boost its photocatalytic activity [42]. CN has been employed for $\mathrm{CO}_{2}$ photoreduction by several groups due to its large surface area and distinct semiconductor properties $[46,47]$. These features may lead to the formation of charge carriers capable of activating $\mathrm{CO}_{2}$ molecules at the active sites of the nitrogen-rich $\mathrm{CN}$ skeleton. Liu et al. demonstrated the synthesis of layered heterojunction photocatalysts $\left(\mathrm{PCN} / \mathrm{ZnIn}_{2} \mathrm{~S}_{4}\right)$ via the in situ growth of $2 \mathrm{D} \mathrm{ZnIn} \mathrm{S}_{4}$ nanosheets on the surfaces of ultrathin $\mathrm{CN}$ layers for improved $\mathrm{CO}_{2}$ conversion under visible light [48]. In addition, the $\mathrm{CN} / \mathrm{ZnIn}_{2} \mathrm{~S}_{4}$ composites also demonstrate enhanced photoactivity for deoxygenated $\mathrm{CO}_{2}$ conversion. On the other hand, Xue et al. [49] proposed a new strategy for solar fuel production with simultaneous organic synthesis using photo-holes oxidation power on amphiphilic metal-free semiconductors. The successfully grafted pyrene functional group onto the $\mathrm{CN}$ surface via a post copolymerization technique (Py-CN) shows unique biphasic photocatalytic activities that allow efficient $\mathrm{CO}_{2}$ photoreduction in aqueous solution while effectively oxidizing alkenes $(\mathrm{C}=\mathrm{C})$ in the organic phase. This is due to the pyrene functional group enhanced lipophilicity, allowing hydrophobic alkene molecules to reach the $\mathrm{CN}$ surface and react with hydroxyl radicals $(\mathrm{OH})$ produced by photogenerated holes [50].

In the present work, we use urea containing $\mathrm{CN}$ to introduce hydroxyl groups containing benzene rings, i.e., 1,4-dihydroxybenzene organic conjugated monomer (DHB) through copolymerization and studied the versatile application of products for photocatalytic $\mathrm{CO}_{2}$ reduction. The incorporation of an aromatic benzene ring into the triazine analogous of $\mathrm{CN}$ can produce a regular inner structure of $\mathrm{CN}$ as a spinal candidate to achieve a polymeric conjugated $\mathrm{C}-\mathrm{N}$ network system. The aromaticity of the benzene ring in the $\mathrm{CN}$ framework can improve the photo-excitation process of electrons from the ground state to the excited state, as well as photogenerated charge separation. As discussed above, the integrated monomer into the $\mathrm{CN}$ skeleton will be either an electron donor or an acceptor; therefore, the dihydroxybenzene monomer acts as an electron donor. Figure 1 provides a proposed reaction mechanism for the incorporation of dihydroxybenzene (DHB) into the $\mathrm{CN}$ framework by donating electrons to the pristine $\mathrm{CN}$ to make a long polymer network that has high stability and a large surface area. An as-synthesized sample showed good photocatalytic activity of $\mathrm{CO}_{2}$ reduction into $\mathrm{CO}$ and $\mathrm{H}_{2}$ sources, which was roughly 4-fold higher than the parental $\mathrm{CN}$. This effort will open up new possibilities to promote the use of copolymerized $\mathrm{CN}$ for $\mathrm{CO}_{2}$ photofixation under visible illumination. 


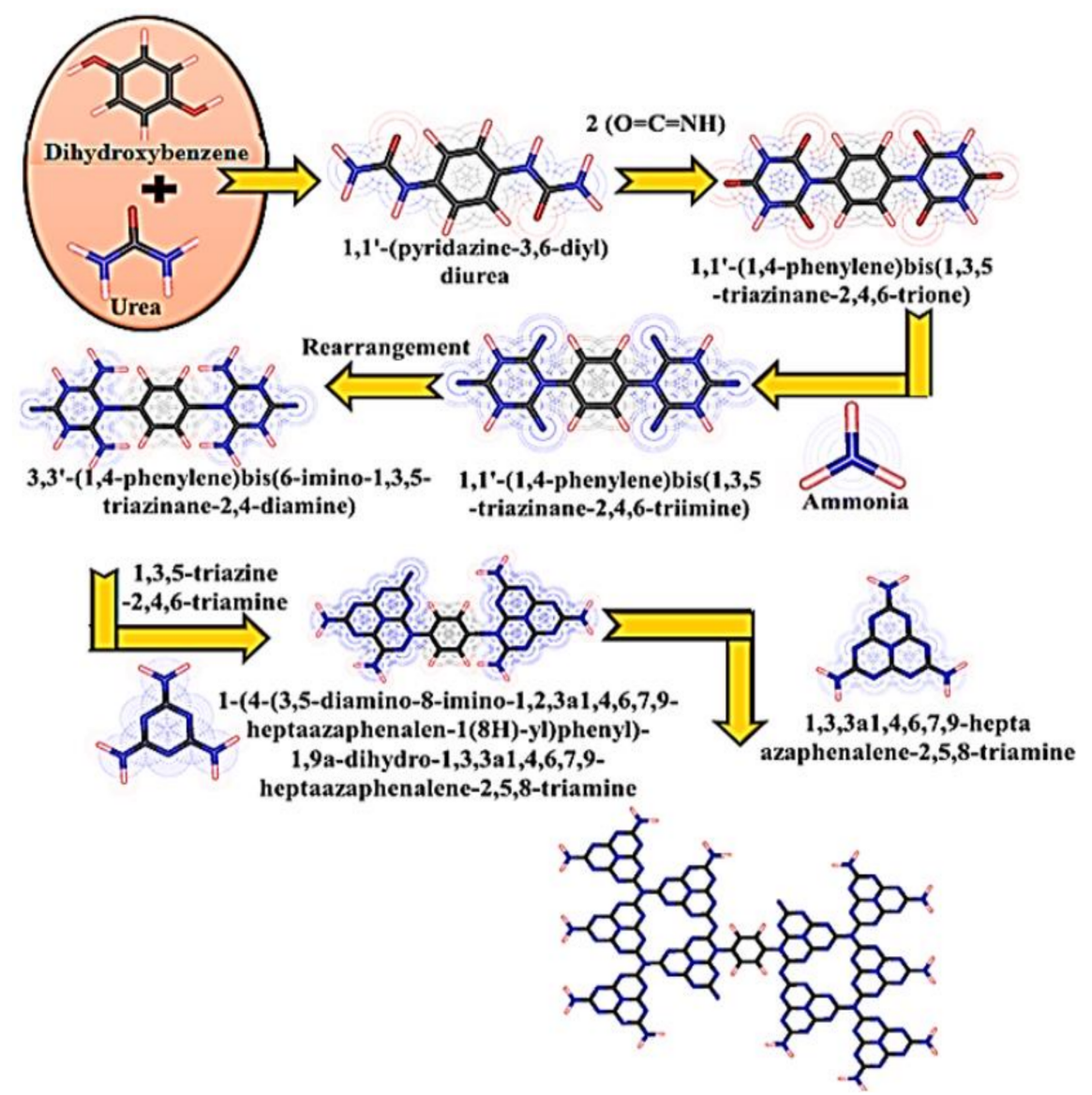

Figure 1. Proposed reaction mechanism of incorporating dihydroxybenzene (DHB) into CN networks.

\section{Experimental}

Synthesis of CN and Copolymerized CN Photocatalysts

A pristine $\mathrm{CN}$ sample was prepared by taking a specific amount of urea as a precursor in a $30 \mathrm{~cm} \times 60 \mathrm{~cm}$ rectangle crucible dish, and the resulting product was annealed at $550{ }^{\circ} \mathrm{C}$ in an air furnace for $2 \mathrm{~h}$ at a heating rate of $4.5^{\circ} \mathrm{C} \mathrm{min}-1$. After calcinations, the yellow color sample is obtained and labeled as $\mathrm{CNU}$ (U denotes the urea containing carbon nitride). Similarly, the copolymerized samples were synthesized by taking $10 \mathrm{~g}$ of urea with varied amounts of 1,4-dihydroxybenzene (DHB) monomer in $15 \mathrm{~mL}$ distilled in an oil bath system by heating at $100{ }^{\circ} \mathrm{C}$ through vigorous stirring to remove water thoroughly. After the evaporation of water, the solid samples were transferred into a $30 \mathrm{~cm} \times 60 \mathrm{~cm}$ rectangle crucible one by one and heated for $2 \mathrm{~h}$ at $550{ }^{\circ} \mathrm{C}$ at a $4.5^{\circ} \mathrm{C} \mathrm{min}-1$ rate. After heating, various color-containing samples were obtained depending on the amount of DHB monomer to be copolymerized. The as-prepared samples were marked as CNU-DHBx where $x$ determines different amounts of DHB to be copolymerized with carbon nitride $(x=0.0050,0.0100,0.0150,0.0200,0.0250,0.0300 \mathrm{~g})$, respectively. Up to a specific amount of DHB with CNU, the color of the samples was obtained from dark yellow to brown. All prepared samples were characterized for different techniques without any further purification or washing.

\section{Result and Discussion}

As-synthesized samples of pristine and copolymerized $\mathrm{CN}$ samples were characterized by employing the X-ray diffraction (XRD) technique [39,51,52]. Figure 2a demonstrates that there are no extra peaks observed in the XRD of pristine $\mathrm{CNU}$ and copolymerized CNU-DHBx, respectively. All samples had two distinct peaks, and the evidence indicated the same structural composition; thus, no detection of extra impurity peaks was observed. 
The peak at $12.9^{\circ}$ indexed as $\left(\begin{array}{lll}1 & 0 & 0\end{array}\right)$ for all samples represents the inter-layer distance in the structural repeating unit of triazine motifs. The distance between these repeating units is approximately $0.68 \mathrm{~nm}$. A dominant peak at $27.7^{\circ}\left(\begin{array}{lll}0 & 0\end{array}\right)$ is due to the periodic interlayer stacking of the conjugated aromatic system of $\mathrm{CN}$ at $0.32 \mathrm{~nm}$. This periodic stacking distribution in the conjugated system of $\mathrm{CN}$ could be determined from the integration of DHB monomer within the skeleton of CNU. For as-synthesized samples, FTIR spectroscopy was used to determine the chemical composition of all samples [39,53]. Figure $2 b$ illustrates the stretching and bending vibration of the heptazine ring unit, which is assigned from several peak locations of the absorption bands at $810 \mathrm{~cm}^{-1}$ and $1200-1630 \mathrm{~cm}^{-1}$, respectively. All of the prepared samples have one common broad peak, which is located between 3000 and $3600 \mathrm{~cm}^{-1}$ and attributed to the stretching modes of the $\mathrm{O}-\mathrm{H}$ and $\mathrm{N}-\mathrm{H}$ groups, which confirms the presence of the amino and hydroxyl group that originated from the condensation process. Another peak located at 1200 to $1600 \mathrm{~cm}^{-1}$, which is due to the breathing mode of $810 \mathrm{~cm}^{-1}$ triazine units, is quite similar to that of CNU. The XRD and FTIR analysis demonstrate that pristine CNU and copolymerized CNU-DHBx have similar a phase composition and chemical structure. Thus, the incorporation of a DHB monomer in the framework of CNU does not carry any change in the crystal and chemical integrity structure of CNU [39,42].
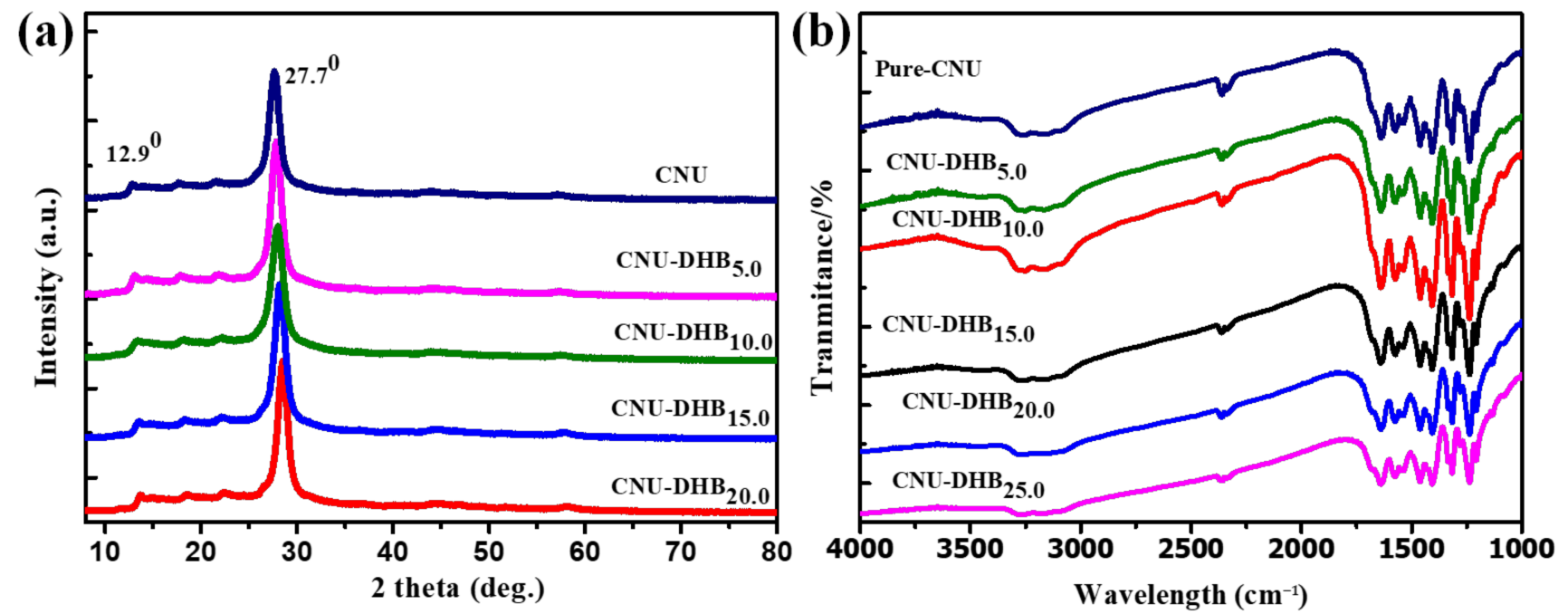

Figure 2. (a) XRD spectrum and (b) FTIR spectra of CNU and CNU-DHBx samples.

Similarly, the induction of conjugated DHB within the skeleton of CN alters several changes in the chemical analysis of $\mathrm{CN}$ that can be confirmed from solid-state ${ }^{13} \mathrm{C} N \mathrm{NM}$ spectra and XPS analysis, respectively. The XPS survey spectra were investigated to figure out the chemical composition states within samples. Figure $3 a, b$ demonstrate the XPS wide spectrum for parental CNU and copolymerized CNU-DHB 15.0 samples mainly composed of carbon $(\mathrm{C})$, nitrogen $(\mathrm{N})$, and oxygen $(\mathrm{O})$, respectively. The $\mathrm{O} 1 \mathrm{~s}$ peak detected at $533 \mathrm{eV}$ for both CNU and CNU-DHBx arises due to the adsorption of atmospheric moisture during synthesis. High-resolution XPS spectra of C 1 s for $\mathrm{CNU}^{-D_{H}} \mathrm{~B}_{15.0}$ and $\mathrm{CNU}$ composed of two distinct peaks are altered; a small shifting occurs in the perception of peaks indexed at

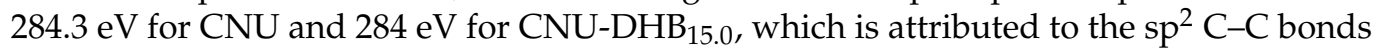
(Figure 3c,d). However, the other peak indexed at $287.5 \mathrm{eV}$ for $\mathrm{CNU}$ and at $288 \mathrm{eV}$ for $\mathrm{CNU}_{-\mathrm{DHB}}{ }_{15.0}$ ascribed the $\mathrm{sp}^{2}$ hybridized carbon located in the cage of the $\mathrm{N}$-containing aromatic ring $(\mathrm{N}-\mathrm{C}=\mathrm{N})$. Furthermore, the high-resolution XPS spectra of $\mathrm{N}$ 1s also alters the shifting of peaks de-convoluted into four peaks. The main peak centering at $398 \mathrm{eV}$ for $\mathrm{CNU}$ and $398.7 \mathrm{eV}$ for $\mathrm{CNU}_{-} \mathrm{DHB}_{15.0}$ corresponds to the $\mathrm{sp}^{2}$ hybridized nitrogen within the carbon $(\mathrm{C}-\mathrm{N}=\mathrm{C})$. Hence, the other peaks indexed at $398.8,400.3$, and $403.8 \mathrm{eV}$ for CNU and $399.7,401.2$, and $404.3 \mathrm{eV}$ for $\mathrm{CNU}_{-} \mathrm{DHB}_{15.0}$ display the bridging tertiary nitro- 
gen $\left(\mathrm{N}-(\mathrm{C})_{3}\right)$, graphitic $\mathrm{N}$, and amino functional groups $(\mathrm{C}-\mathrm{N}-\mathrm{H})[39,42]$, as illustrated in Figure $3 e, f$.
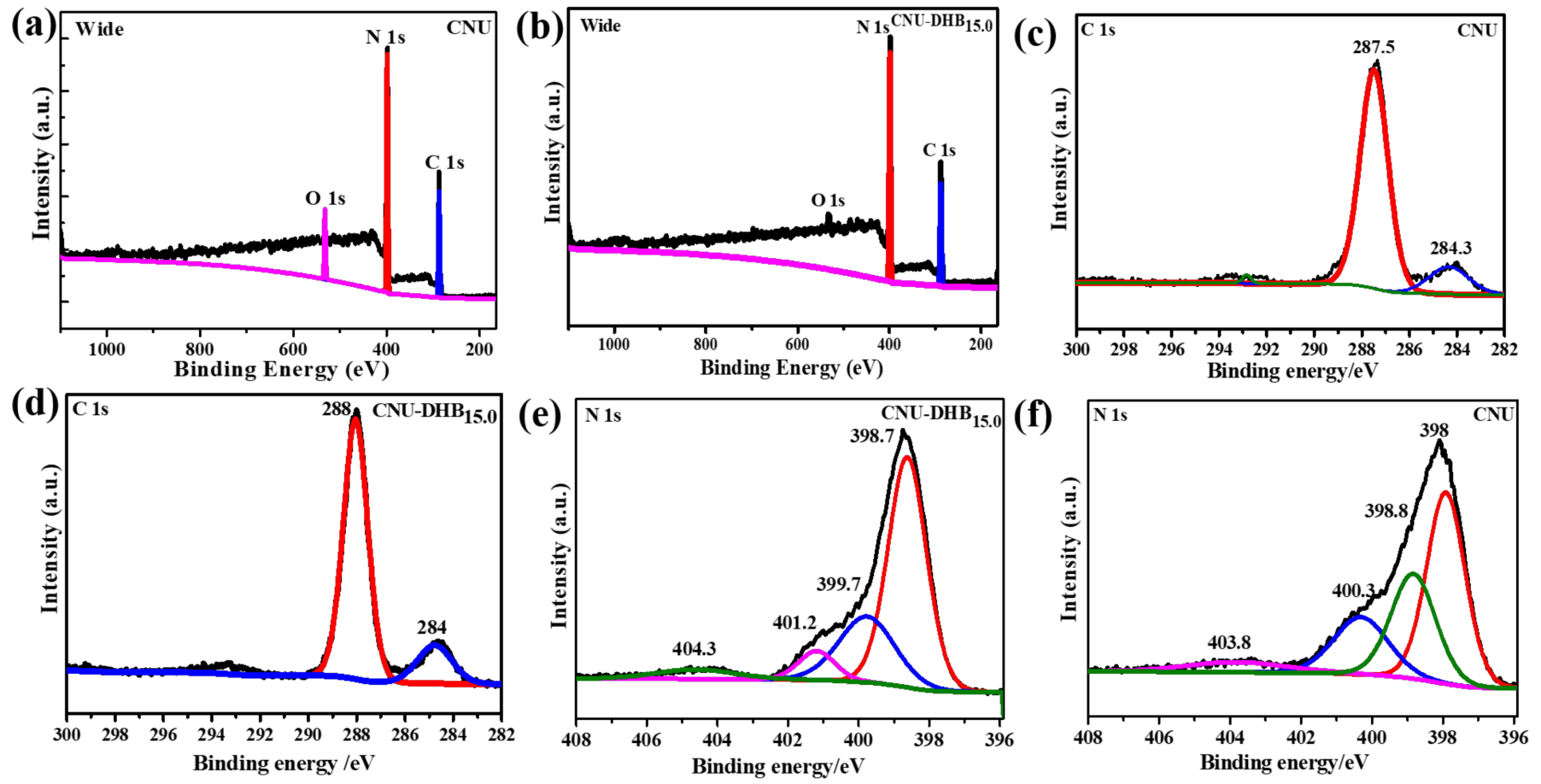

Figure 3. (a,b) Wide spectrum, (c,d) C 1s, and (e,f) N 1s high-resolution XPS spectra of the CNU-DHB 15.0 and CNU samples.

The solid-state ${ }^{13} \mathrm{C}$ NMR spectra for CNU and CNU-DHB 15.0 samples were used to examine the extra evolution of carbon contents after the copolymerization process (Figure S1). All of the peak alignments in the NMR spectra for both samples are the same, but a new peak was indexed at $135.7 \mathrm{ppm}$ for the $\mathrm{CNU}-\mathrm{DHB}_{15.0}$ sample, thus confirming the increased amount of carbon. The morphology and microstructure of pure CNU and CNU-DHB 15.0 were analyzed by FESEM and TEM, as illustrated in Figure 4. The FESEM morphology of pure CNU obviously demonstrates an agglomerated shape having irregular small stacking flakiness, as displayed in Figure 4a,b, while this morphology became elongated in size after the inducing of a DHB monomer within CNU, having a large cloudy superficial area, as shown in Figure 4c,d. The typical TEM images of pure CNU (Figure 4e,f) and $\mathrm{CNU}-\mathrm{DHB}_{15.0}$ (Figure $4 \mathrm{~g}, \mathrm{~h}$ ) exhibit platelet ribbon-like distorted morphology for pure CNU samples. After copolymerization, the surface morphology become dense, stacked, and proliferous, which results in an increase in the surface area.

The UV-Vis diffuse reflectance spectroscopy (DRS) of the samples was used to assess the effect of the DHB monomer on the optical property of CNU, as shown in Figure 5a. After DHB incorporation into the backbone of CNU, the optical bandgap is significantly reduced, which facilitates the harvesting of light and photogenerated carriers [39,42]. To study the transfer and exciton separation behavior of the photogenerated electrons and holes of the as-prepared copolymerized samples, we carried out photoluminescence (PL) spectra at room temperature under $370 \mathrm{~nm}$ excitation (Figure 5b). All these samples show a wide broad peak indexed at around $455 \mathrm{~nm}$ and extend their tail to $600 \mathrm{~nm}$. The spectra demonstrate two types of band: i.e., a shoulder band, which is attributed to the emission process of $\mathrm{CN}$ from the valence band (LUMO) toward the conduction band (HOMO) at a shorter wavelength of $440 \mathrm{~nm}$. The other PL band corresponds to the emission of charges as found in donor-acceptor polymers [54]. Actually, in CNU, the weak shoulder band is produced due to the emission of charges at about $463 \mathrm{~nm}$. Similarly, the rates of transfer of photogenerated charges toward transition states are much higher in copolymerized samples compared to pristine samples. To understand the exciton separation behavior, we 
conducted surface photovoltage. When compared to the copolymerized sample, pristine CNU exhibits a weak SPV signal at 350-550 nm (Figure 5c), which is due to the low charge separation compared to pristine. Nonetheless, the copolymerized CNU exhibits a clear enhancement of the SPV signal, indicating an increased charge separation due to the aromaticity of the benzene ring in the $\mathrm{CN}$ framework, which acts as an electron-donating species. The effect of the aromaticity of the benzene ring of DHB in the framework of $\mathrm{CN}$, acting as an electron-donating species, was further verified by OCP spectra, as shown in Figure $5 \mathrm{~d}$. The $\mathrm{C} / \mathrm{N}$ ratio and bandgap for all of the as-synthesized samples are depicted in Table $\mathrm{S} 2$, in which the superior sample $\mathrm{CNU}-\mathrm{DHB}_{15.0}$ demonstrates a boosted $\mathrm{C} / \mathrm{N}$ ratio and low bandgap, respectively.
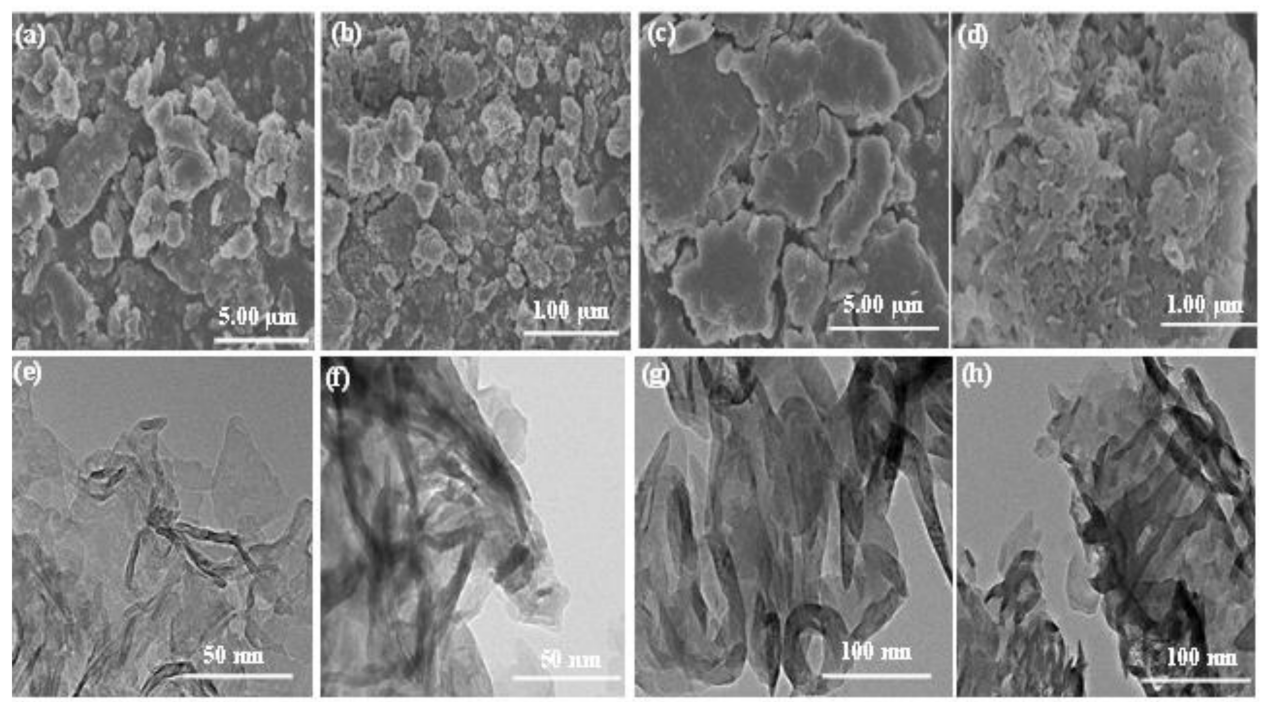

Figure 4. FESEM of $\mathrm{CNU}(\mathbf{a}, \mathbf{b})$ and $\mathrm{CNU}-\mathrm{DHB}_{15.0}(\mathbf{c}, \mathbf{d})$, TEM images of $\mathrm{CNU}(\mathbf{e}, \mathbf{f})$ and $\mathrm{CNU}-\mathrm{DHB} \mathrm{B}_{15.0}(\mathbf{g}, \mathbf{h})$.
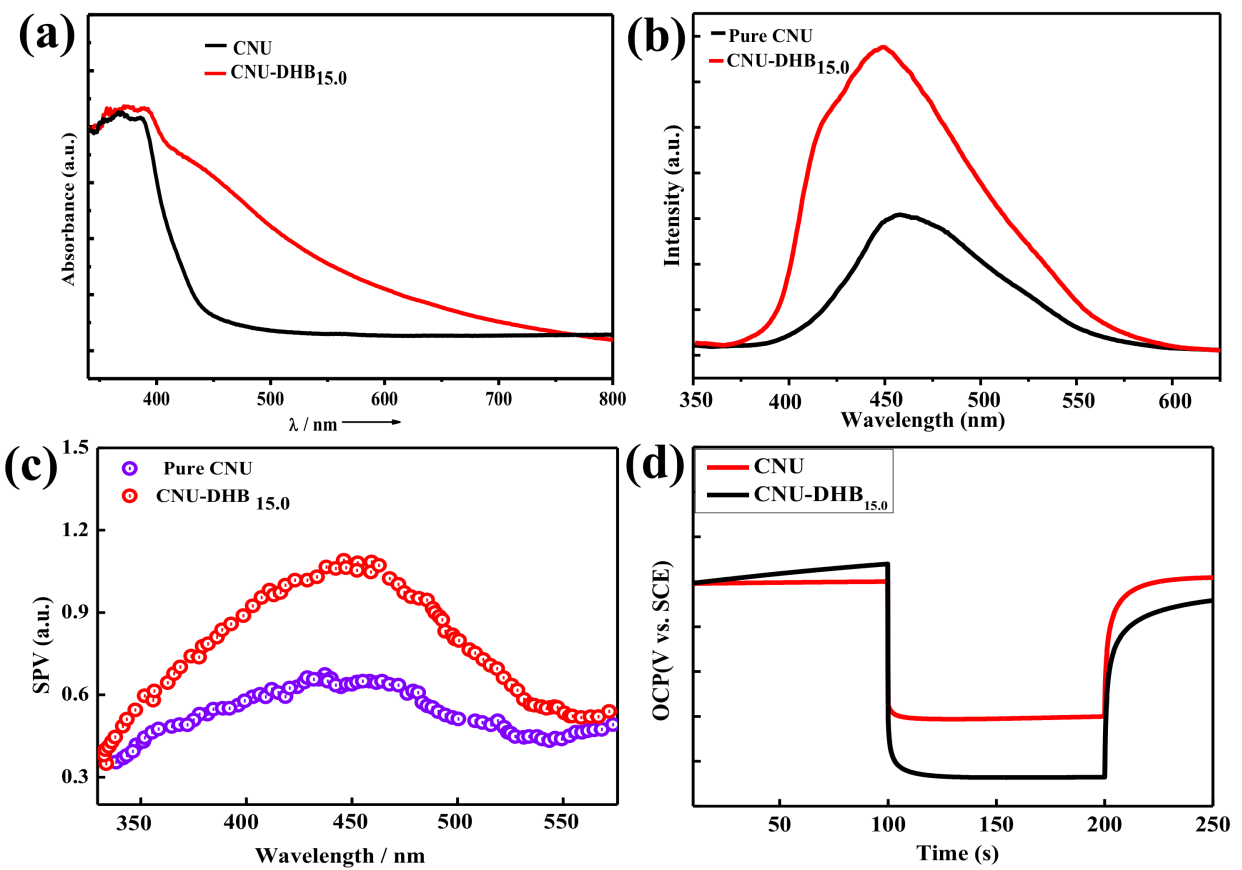

Figure 5. (a) UV-Vis DRS spectra of the CNU and CNU-DHBx samples under $370 \mathrm{~nm}$ excitation. (b) The photoluminescence spectrum of the CNU and CNU-DHBx samples at room temperature. (c) SPV spectra of the CNU and CNU-DHBx samples. (d) OCP response curve of the CNU and CNU-DHBx samples. 
The Brunauer-Emmett-Teller (BET) method was conducted to examine the specific surface area of as-synthesized samples (Figure 6a). Both samples (CNU and CNU-DHB ${ }_{15.0}$ ) represent the $\mathrm{N}_{2}$ adsorption-desorption isotherms having $\mathrm{H}_{3}$ hysteresis-type loops [55]. The surface area of blank CNU is $49.9 \mathrm{~m}^{2} / \mathrm{g}$ and after the copolymerization process, the surface area of CNU-DHB 15.0 improved to $123.7 \mathrm{~m}^{2} / \mathrm{g}$, respectively. Actually, large surface areas supply an abundance of energized sites for the photocatalytic reaction that result in photocatalytic performance. Figure $6 \mathrm{~b}$ illustrates the $\mathrm{BJH}$ pore size distribution and highlights that the catalysts' pore size decreases and pore volume increases, hence originating the structure of samples as mesoporous. Actually, during the co-condensation process of samples, various gases evolved from their partial decomposition and adopted mesoporous structures $[39,42]$. The $\mathrm{CO}_{2}$ adsorption isotherm was evaluated for pristine $\mathrm{CNU}$ and copolymerized $\mathrm{CNU}-\mathrm{DHB}_{15.0}$, as illustrated in Figure $6 \mathrm{c}$, indicating that $\mathrm{CNU}$ $\mathrm{DHB}_{15.0}$ has remarkable $\mathrm{CO}_{2}$ adsorption ability compared to pure $\mathrm{CNU}$. The surface area for all of the as-synthesized samples was depicted in Table $\mathrm{S} 2$, in which the superior sample $\mathrm{CNU}-\mathrm{DHB}_{15.0}$ demonstrates a high surface area.

(a)

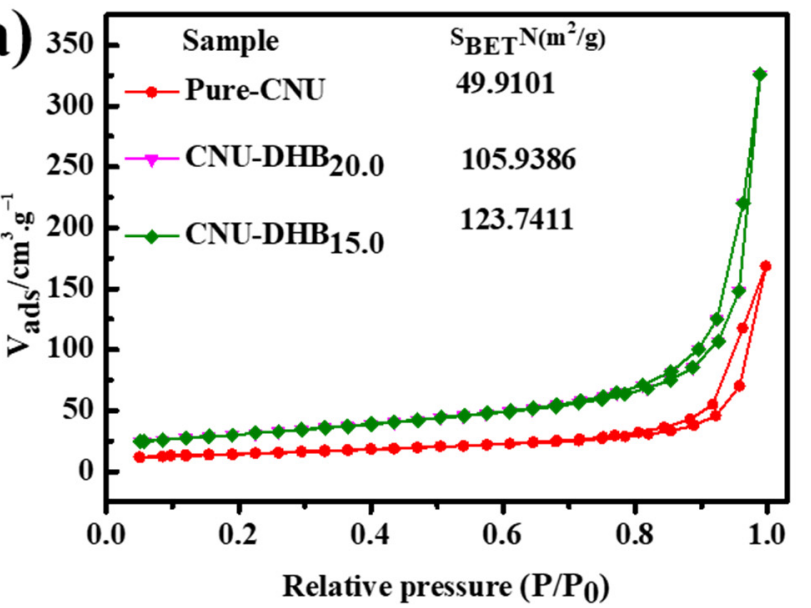

(b)

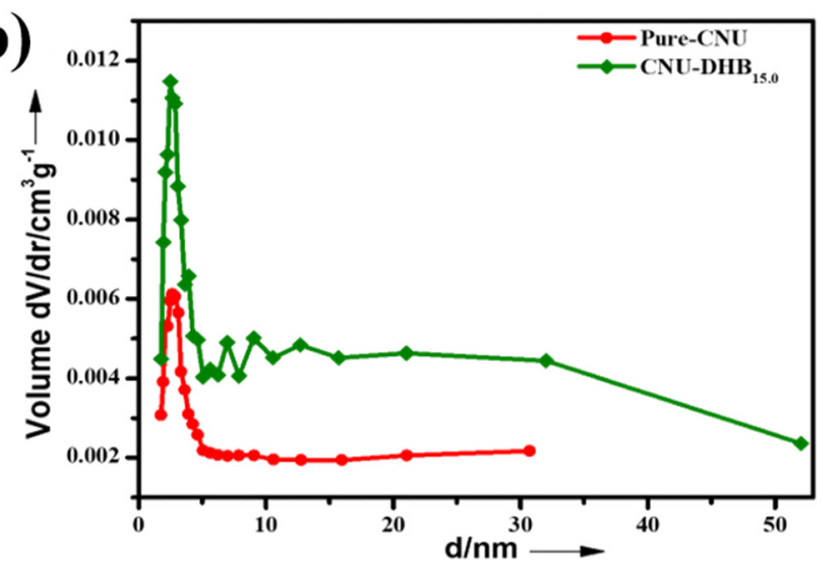

(c)

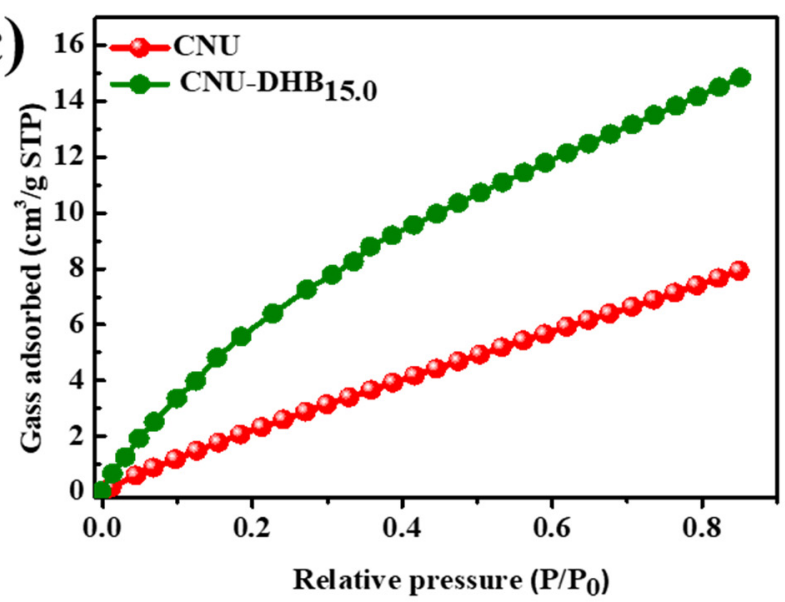

Figure 6. (a) $\mathrm{N}_{2}$ adsorption-desorption isotherms (77 K), (b) $\mathrm{BJH}$ pore size distribution, and (c) $\mathrm{CO}_{2}$ adsorption isotherms $(273 \mathrm{~K})$ for $\mathrm{CNU}$ and $\mathrm{CNU}-\mathrm{DHB}_{15.0}$ samples.

The photocatalytic activity of $\mathrm{CO}_{2}$ reduction was carried out under visible light illumination $(\lambda>420 \mathrm{~nm})$. Typically, $30 \mathrm{mg}$ of photocatalyst was dispersed in a solvent $\left.(\mathrm{MeCN}) / \mathrm{H}_{2} \mathrm{O}=5: 1\right)$ containing $\mathrm{Co}(\mathrm{bpy})_{3} \mathrm{Cl}_{2} \cdot 6 \mathrm{H}_{2} \mathrm{O}$ as a photosensitizer and triethanolamine (TEOA) as a sacrificial electron donor [18]. The reactions were carried out for half an hour to five hours, generating a significant amount of $\mathrm{CO}\left(32.5 \mu \mathrm{mol} / \mathrm{h}^{-1}\right)$ in the first hour and achieving a high CO efficiency, i.e., $85 \mu \mathrm{mol} / \mathrm{h}$ in five hours (Figure 7a). Similarly, bulk CNU photocatalysts have poor photocatalytic performance compared to 
$\mathrm{CNU}-\mathrm{DHB}_{15.0}$. The photocatalytic reduction of $\mathrm{CO}_{2}$ was enhanced after the incorporation of DHB in the framework of $\mathrm{CNU}$, indicating the best activity in optimal condition (Figure $7 \mathrm{~b}$ ). All of the other copolymerized samples demonstrate good photocatalytic performance and are much better than pristine CNU. In all of these photocatalysts, CNU$\mathrm{DHB}_{15.0}$ manifested a boosted performance for the photocatalytic $\mathrm{CO}_{2}$ reduction under visible light (Table S2). Similarly, the activity of samples decreases due to the appearance of a negative site from the excess amount of DHB monomer that destroys the conjugated sys-

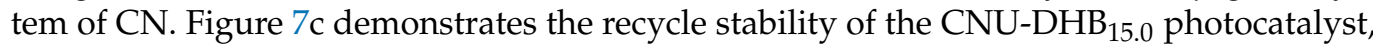
which depicts a high photocatalytic stability toward $\mathrm{CO}_{2}$ reduction in every phase. The long durability experiments demonstrate a decline in the few cycles, which is correlated with the erosion of the co-catalyst cobalt due to the long interaction of solar light during a reaction.

(a)

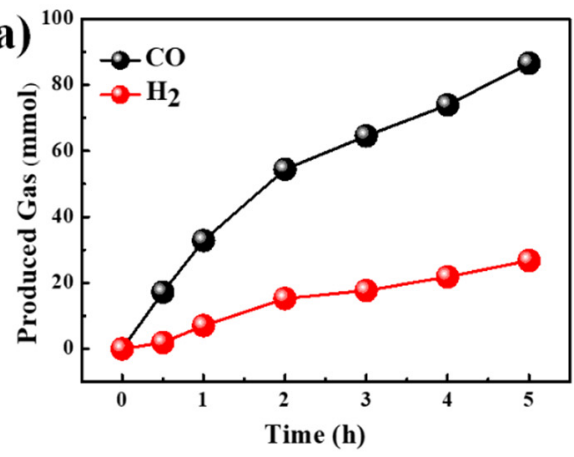

(d)

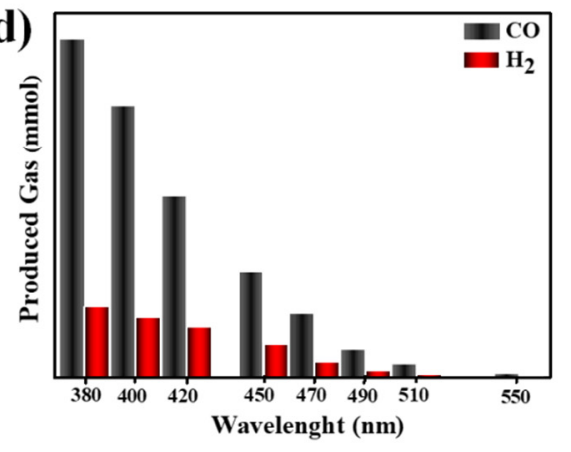

(b)

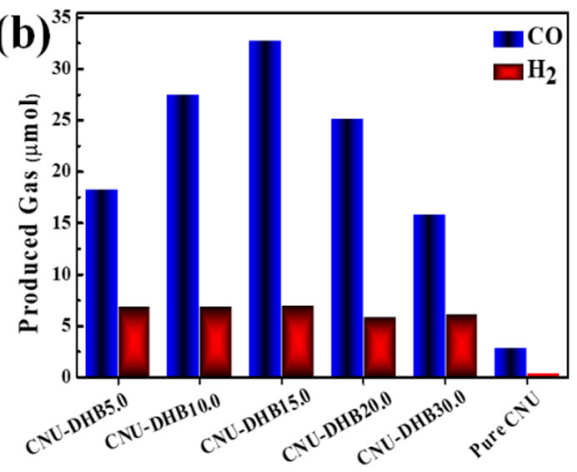

(e)

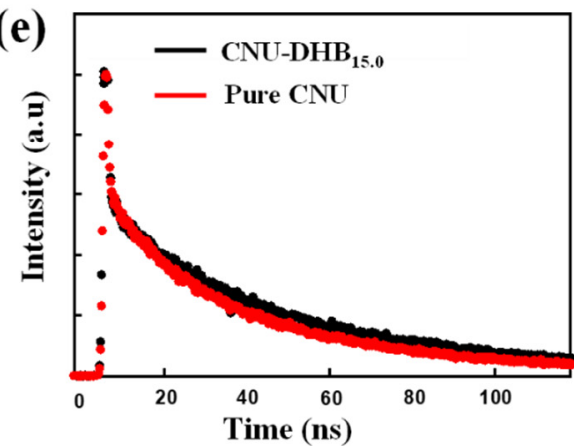

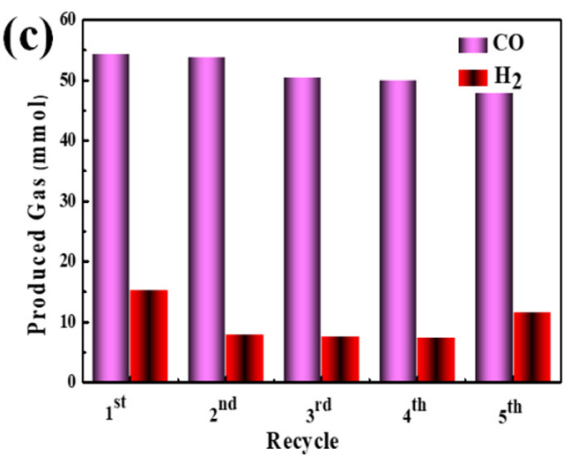

(f)

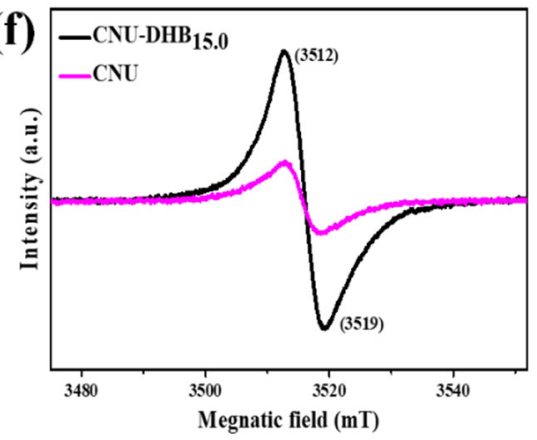

Figure 7. Reduction (a) Time-production plot between CNU and CNU-DHB 15.0 , (b) Comparison of photoreduction with different photocatalysts synthesized, (c) Recycling stability test, (d) Different wavelength experiments, (e) TRPL spectra of CNU-DHB 15.0 and pure CNU, (f) EPR spectra of $\mathrm{CNU}$ and $\mathrm{CNU}-\mathrm{DHB}_{15.0}$.

Long-range wavelength experiments have been conducted for the superior sample CNU-DHB 15.0 to investigate the effect of light source on the photocatalytic products (Figure 7d). The results manifest that the light of a longer wavelength decreases the photocatalytic evolution of $\mathrm{CO}$ and $\mathrm{H}_{2}$, suggesting that light-harvesting phenomena is responsible for the $\mathrm{CO}_{2}$ photoreduction by generating stimulated electrons [18]. The EPR and life time spectra of as-synthesized samples were conducted, as demonstrated in Figure 7e,f. The life time decay of superior sample is much enhance than the blank samples and same the EPR peak intensity of the CNU-DHB 15.0 sample improved and broadened immediately as compared to pristine CNU. Upon copolymerization, the unpaired electrons of carbon atoms increase the EPR peak intensity and also increase the delocalization of $\pi$-conjugated clusters. Most photochemical radical pairs generate light on the catalyst surface by trapping it under visible light [56-58]. A comparison of the reported results of the photocatalytic $\mathrm{CO}_{2}$ reduction with our current research work is presented in Table S1.

Similarly, several isotopic controlled experiments were held using ${ }^{13} \mathrm{CO}_{2}$ as feedback to analyze the insights of carbon contents of the produced carbon monoxide (CO) products under similar conditions. After irradiation of one hour, the gas chromatography and mass 
spectrometry (GC-MS) demonstrate that the peak produced at $2.4 \mathrm{mint}$ having $\mathrm{m} / \mathrm{z}=29$ originated due to the reactant of ${ }^{13} \mathrm{CO}_{2}$, as illustrated in Figure $8 \mathrm{a}, \mathrm{b}$. The result strongly suggests that photocatalytic $\mathrm{CO}_{2}$ reduction into the $\mathrm{CO}$ product is absolutely performed by using the original reactant $\mathrm{CO}_{2}$ gas.
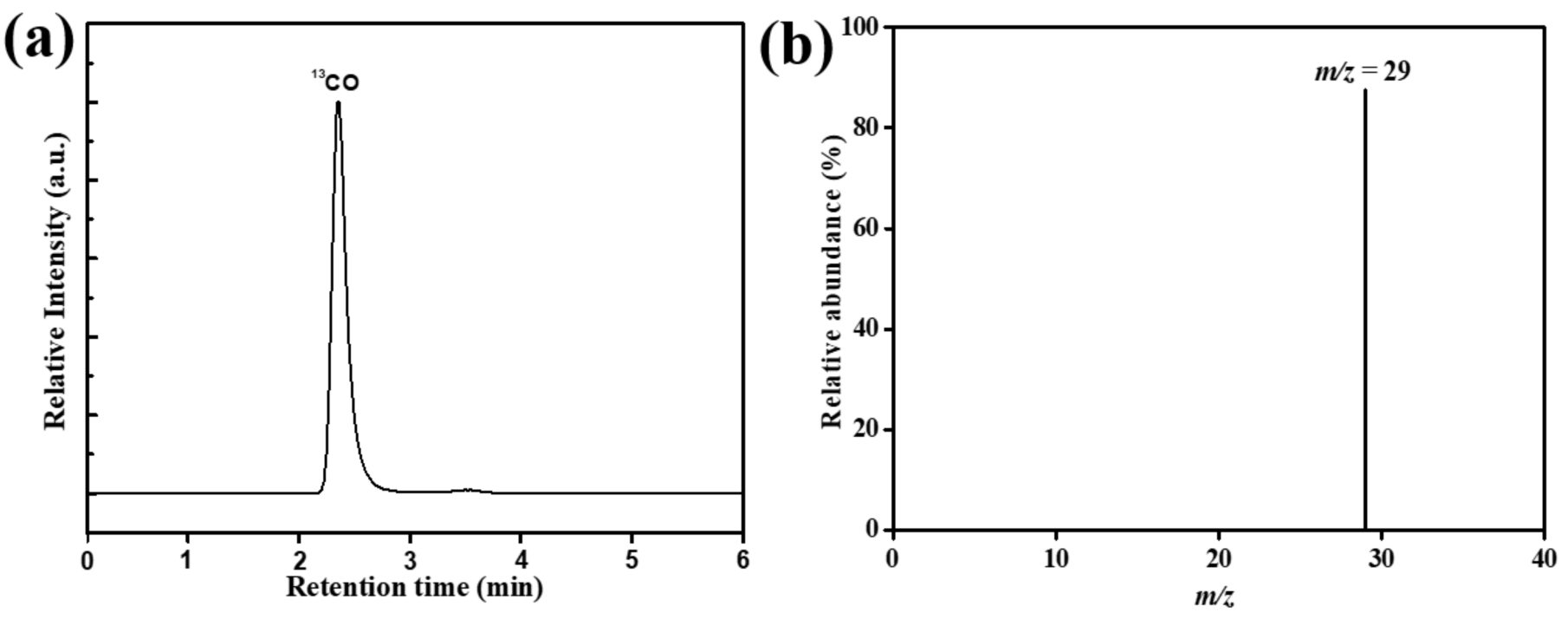

Figure 8. (a) Gas chromatogram and (b) mass spectrum analysis of the carbon products using CNU-DHB 15.0 as catalyst and ${ }^{13} \mathrm{CO}_{2}$ as reactant.

The photocatalytic activities of the synthesized samples were evaluated for the degradation of rhodamine $B$ under visible light irradiation $(\lambda=420 \mathrm{~nm})$, as shown in Figure S2a. The CNU-DHBx catalyst shows better photocatalytic activities than pure CNU. The degradation rate of rhodamine B is enhanced after the copolymerization process. Similarly, few experiments for the degradation of $\mathrm{RhB}$ were conducted under dark illumination, and no noticeable photodegradation activity was observed, so it was concluded that the reaction and catalysts are only active under visible light illumination. The overall degradation was carried out for $70 \mathrm{~min}$ under visible light at varying exposure times. The kinetic

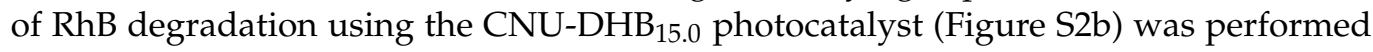
successfully and was calculated with a pseudo-first-order equation as fellows.

$$
\ln \left(\mathrm{C}_{0} / \mathrm{C}\right)=\mathrm{kt}
$$

where the apparent rate constant of the pseudo-first order is shown in the above Equation (1) k, the time of irradiation applied during the degradation process shall be $t$, and the initial and final concentration of the $\mathrm{RhB}$ solution shall be $\mathrm{C}_{0} / \mathrm{C}$ [16]. The result confirms that CNU$\mathrm{DHB}_{15.0}$ has a better kinetic rate constant value and also investigates the pseudo-first-order catalytic rate constants from the slope of the plots, which are four times higher than that of pure $\mathrm{CNU}$. The apparent rate constants for $\mathrm{RhB}$ degradation through different synthesized samples are depicted in Figure S2c. The recycling experiments were conducted for the superior photocatalyst CNU-DHB 15.0 in order to check its stability toward the photodegradation of $\mathrm{RhB}$. Figure S2d shows the cyclic stability experiments for the RhB, and for this function, the used CNU-DHB 15.0 catalysts were centrifuged, washed several times with ethanol and water, and dried to reuse in a fresh reaction. The results reveal that $\mathrm{CNU}-\mathrm{DHB}_{15.0}$ showed good photocatalytic activity and stability in practically all of the four cycling runs, and hence, no obvious decline was observed after long-term use. It indicates that CNU-DHBx is highly stable and can be reused for the treatment of RhB. 


\section{Photocatalytic Mechanism}

The possible scheme for the photocatalytic $\mathrm{H}_{2}$ production and $\mathrm{CO}_{2}$ with the $\mathrm{CNU}$ $\mathrm{DHB}_{15.0}$ photocatalyst was evaluated, as shown in Figure 9. When irritated under solar light, the electrons are excited to the conduction band (CB), leaving positive holes in the valence band (VB) of the CNU-DHB 15.0 photocatalyst. The excited electrons in the $\mathrm{CB}$ of $\mathrm{CNU}-\mathrm{DHB}_{15.0}$ reduce protons to reduce $\mathrm{CO}_{2}$ into the $\mathrm{CO}$ source, while the positive holes in the VB contribute to oxidizing TEOA. The particles of cobalt (CO) play an important role in the separation of exited charges through its metallic character called surface catalysis. In the reaction system, the small addition of catalysts with solvent creates splits on the interface of material; then, $\mathrm{H}^{+}$ions are produced, which trap the electrons and generate $\mathrm{H}_{2}$ fuel. Although a large number of the photoelectrons and holes produced are attributed to the absorption of solar photons, a very small portion of these charges is used for effective photocatalysis. To accelerate the photocatalytic production of $\mathrm{H}_{2}$ fuel, the separation of electrons and holes through $\mathrm{CO}$ and sacrificial agent TEOA is very important. Similarly, the induced holes in the VB of the superior sample results are oxidized, which participate in the photocatalytic degradation of RhB reduction under visible light illumination $(\lambda=420 \mathrm{~nm})$.

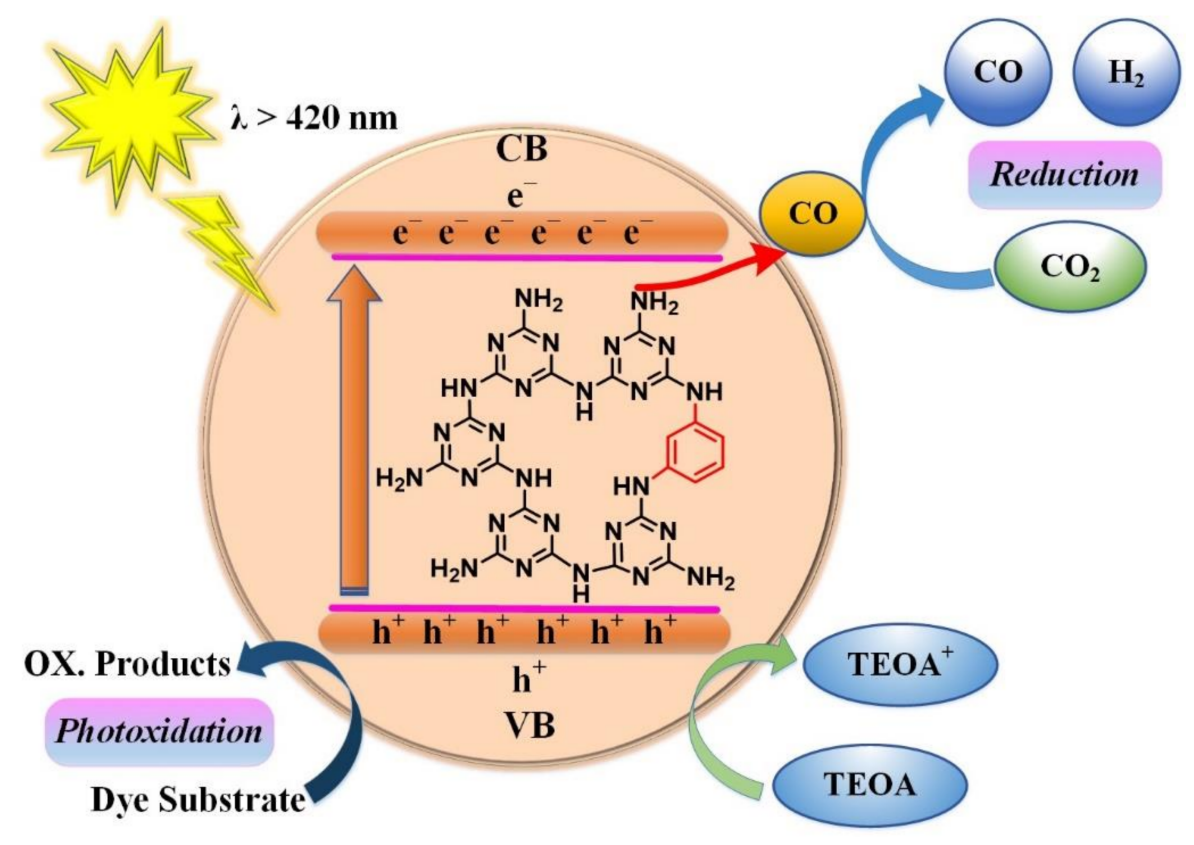

Figure 9. The proposed reaction mechanism for photo reduction and degradation through CNU-DHB 15.0 .

\section{Conclusions}

The modification of carbon nitride (CNU) for photocatalytic $\mathrm{CO}_{2}$ reduction is an enticing research topic owing to the growing severity of fuel and ecological ailments. In this study, the organic aromatic co-monomer dihydroxybenzene (DHB) was thermally incorporated within carbon nitride (CNU referred to as urea-based carbon nitride) through the copolymerization process recognized as CNU-DHB. Interestingly, the copolymerized samples demonstrated an efficient $\mathrm{CO}_{2}$ reduction due to the aromaticity conjugated $\pi$ electrons of the benzene ring in the framework of $\mathrm{CN}$, which acts as an electron-donating species; therefore, it can speed up the process of photogenerated charge separation. This assimilation altered a significant change in the electronic structure of $\mathrm{CNU}$, boosted its electron transport, and increased the photocatalytic properties of $\mathrm{CNU}$ under visible light irradiation. The CNU-DHB 15.0 catalyst yielded $85 \mu \mathrm{mol} / \mathrm{h}$ of $\mathrm{CO}$ and $19.92 \mu \mathrm{mol} / \mathrm{h}$ of $\mathrm{H}_{2}$ source after $5 \mathrm{~h}$ of irradiation, highlighting the maximum yield of photocatalytic performance that is almost four times higher than that of parental CNU. Such an approach predicts a substantial distraction in the precise surface area, energy gap, and chemical 
properties, and it promotes the effective segregation of photoinduced load carriers from HUMO toward LOMO of CNU, making it an ideal alternative for photocatalytic $\mathrm{CO}_{2}$

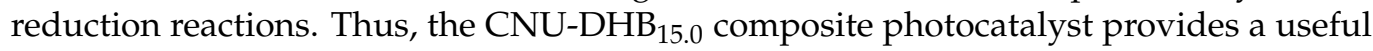
guide for the synthesis of efficient photocatalysts for photocatalytic applications.

Supplementary Materials: The following are available online at https://www.mdpi.com/article/10.3 390/nano11123245/s1, Figure S1: Solid-state ${ }^{13}$ C NMR spectra of pure CNU and CNU-DHB ${ }_{15.0}$ samples. Figure S2: (a) Visible light photocatalytic degradation (b) first-order kinetics data (c) the apparent rate constants for $\mathrm{RhB}$ degradation (d) Cycling runs of $\mathrm{CNU}-\mathrm{DHB}_{15.0}$ catalyst for the photocatalytic degradation of rhodamine (RhB) dye $(\lambda=420 \mathrm{~nm})$ Table S1: comparison of photocatalytic performance of $\mathrm{CO}_{2}$ reduction. Table S2: Different parameters of our synthesized photocatalysts.

Author Contributions: M.S. have performed the experiments, data analysis and article writing, T.A., T.A.M.T., A.G.A.-S., K.S.E.-N. and A.A.A.-G., collaborated investigation and give a data curation. M.B. and A.P. review and editing paper. A.H., M.A.A. and W.I.N.B.W.I., done visualization, supervision, project administration. All authors have read and agreed to the published version of the manuscript.

Funding: We gratefully acknowledge the support of this research by funding from the Foundation of Yangtze Delta Region Institute (Huzhou) of UESTC, China, (Nos. U03210057). The authors are also grateful to the Taif University Researchers Supporting Project number (TURSP-2020/03), Taif University, Taif, KSA. The authors acknowledge the support and funding of King Khalid University; grant no: KKU/RCAMS/006/21. Finally, the authors would like to thank the Ministry of higher education, Malaysia (MOHE) for providing financial support under PRGS grants: (PRGS/1/2021/STG04/UITM/02/1), Universiti Teknologi MARA (UiTM).

Institutional Review Board Statement: Not applicable.

Informed Consent Statement: Not applicable.

Data Availability Statement: The data presented in this study are available on request from the corresponding author.

Conflicts of Interest: The authors declare no conflict of interest.

\section{References}

1. Listorti, A.; Durrant, J.; Barber, J. Artificial photosynthesis: Solar to fuel. Nat. Mater. 2009, 8, 929-930. [CrossRef]

2. Hori, Y. Electrochemical $\mathrm{CO}_{2}$ Reduction on Metal Electrodes; Springer: New York, NY, USA, 2008.

3. Hamid, A.; Khan, M.; Hayat, A.; Raza, J.; Hussain, F. robing the physio-chemical appraisal of green synthesized PbO nanoparticles in PbO-PVC nanocomposite polymer membranes. Spectrochim. Acta Part A Mol. Biomol. Spectrosc. 2020, 235, 118303. [CrossRef]

4. Centi, G.; Perathoner, S. Perspectives and State of the Art in Producing Solar Fuels and Chemicals from $\mathrm{CO}_{2}$. Green Carbon Dioxide: Advances in CO2 Utilization; Wiley Online Library: Hoboken, NJ, USA, 2014; pp. 1-24.

5. Hayat, A.; Khan, J.K.; Rahman, M.U.; Mane, S.B.; Khan, W.U.; Sohail, M.; Rahman, N.U.; Shaishta, N.; Chi, Z.; Wu, M. Synthesis and Optimization of the Trimesic Acid Modified Polymeric Carbon Nitride for Enhanced Photocatalytic Reduction of $\mathrm{CO}_{2}$. J. Colloid Interface Sci. 2019, 548, 197-205. [CrossRef] [PubMed]

6. Sato, S.; Morikawa, T.; Saeki, S.; Kajino, T.; Motohiro, T. Visible-light-induced selective $\mathrm{CO}_{2}$ reduction utilizing a ruthenium complex electrocatalyst linked to a p-type nitrogen-doped $\mathrm{Ta}_{2} \mathrm{O}_{5}$ semiconductor. Angew. Chem. 2010, 122, 5227-5231. [CrossRef]

7. Kuriki, R.; Matsunaga, H.; Nakashima, T.; Wada, K.; Yamakata, A.; Ishitani, O.; Maeda, K. Nature-Inspired, Highly Durable $\mathrm{CO}_{2}$ Reduction System Consisting of a Binuclear Ruthenium(II) Complex and an Organic Semiconductor Using Visible Light. J. Am. Chem. Soc. 2016, 138, 5159-5170. [CrossRef]

8. Ullah, I.; Taha, T.A.; Alenad, A.M.; Uddin, I.; Hayat, A.; Hayat, A.; Sohail, M.; Irfan, A.; Khan, J.; Palamanit, A. Platinum-Alumina Modified $\mathrm{SO}_{4}{ }^{2-}-\mathrm{ZrO}_{2} / \mathrm{Al}_{2} \mathrm{O}_{3}$ Based Bifunctional Catalyst for Significantly Improved $\mathrm{n}$-butane Isomerization Performance. Surf. Interfaces 2021, 25, 101227. [CrossRef]

9. Li, J.; Wu, N. Semiconductor-based photocatalysts and photoelectrochemical cells for solar fuel generation: A review. Catal. Sci. Technol. 2014, 5, 1360-1384. [CrossRef]

10. Cheng, H.; Huang, B.; Liu, Y.; Wang, Z.; Qin, X.; Zhang, X.; Dai, Y. An anion exchange approach to $\mathrm{Bi}_{2} \mathrm{WO}_{6}$ hollow microspheres with efficient visible light photocatalytic reduction of $\mathrm{CO}_{2}$ to methanol. Chem. Commun. 2012, 48, 9729-9731. [CrossRef]

11. Liu, Q.; Zhou, Y.; Kou, J.; Chen, X.; Tian, Z.; Gao, J.; Yan, S.; Zou, Z. High-Yield Synthesis of Ultralong and Ultrathin $\mathrm{Zn}_{2} \mathrm{GeO}_{4}$ Nanoribbons toward Improved Photocatalytic Reduction of $\mathrm{CO}_{2}$ into Renewable Hydrocarbon Fuel. J. Am. Chem. Soc. 2010, 132, 14385-14387. [CrossRef]

12. Liu, S.; Yu, J. Effect of F-Doping on the Photocatalytic Activity and Microstructures of Nanocrystalline $\mathrm{TiO}_{2}$ Powders. Nanostruct. Photocatal. 2016, 187-200. [CrossRef] 
13. Ah, A.; Ns, B.; Skbm, C.; Ah, D.; Jk, E.; Aur, F.; Tl, G. Molecular engineering of polymeric carbon nitride based Donor-Acceptor conjugated copolymers for enhanced photocatalytic full water splitting. J. Colloid Interface Sci. 2020, 560, 743-754.

14. Lopez-Tenllado, F.J.; Murcia-López, S.; Gómez, D.M.; Marinas, A.; Marinas, J.M.; Urbano, F.J.; Navío, J.A.; Hidalgo, M.C.; Gatica, J.M. A comparative study of $\mathrm{Bi}_{2} \mathrm{WO}_{6}, \mathrm{CeO}_{2}$, and $\mathrm{TiO}_{2}$ as catalysts for selective photo-oxidation of alcohols to carbonyl compounds. Appl. Catal. Gen. Int. J. Devoted Catal. Sci. Its Appl. 2015, 505, 375-381.

15. Pare, B.; Singh, P.; Jonnalgadda, S. Degradation and mineralization of victoria blue B dye in a slurry photoreactor using advanced oxidation process. J. Sci. Ind. Res. 2009, 68, 724-729.

16. Khan, M.; Hayat, A.; Mane, S.; Li, T.; Khan, W.U. Functionalized nano diamond composites for photocatalytic hydrogen evolution and effective pollutant degradation. Int. J. Hydrog. Energy 2020, 45, 29070-29081. [CrossRef]

17. Sohail, M.; Xue, H.; Jiao, Q.; Li, H.; Khan, K.; Wang, S.; Zhao, Y. Synthesis of well-dispersed TiO ${ }_{2} @$ reduced graphene oxide (rGO) nanocomposites and their photocatalytic properties. Mater. Res. Bull. 2017, 90, 125-130. [CrossRef]

18. Hayat, A.; Rahman, M.U.; Khan, I.; Khan, J.; Sohail, M.; Yasmeen, H.; Liu, S.Y.; Qi, K.; Lv, W. Conjugated Electron Donor-Acceptor Hybrid Polymeric Carbon Nitride as a Photocatalyst for $\mathrm{CO}_{2}$ Reduction. Molecules 2019, 24, 1779. [CrossRef]

19. Hayat, A.; Chen, Z.; Luo, Z.; Fang, Y.; Wang, X. $\pi$-deficient pyridine ring-incorporated carbon nitride polymers for photocatalytic $\mathrm{H}_{2}$ evolution and $\mathrm{CO}_{2}$ fixation. Res. Chem. Intermed. 2021, 47, 15-27. [CrossRef]

20. Kumar, A.; Raizada, P.; Thakur, V.K.; Saini, V.; Khan, A.A.P.; Singh, N.; Singh, P. An overview on polymeric carbon nitride assisted photocatalytic $\mathrm{CO}_{2}$ reduction: Strategically manoeuvring solar to fuel conversion efficiency. Chem. Eng. Sci. 2021, 230, 116219. [CrossRef]

21. Hasija, V.; Sudhaik, A.; Raizada, P.; Hosseini-Bandegharaei, A.; Singh, P. Carbon quantum dots supported AgI/ZnO/phosphorus doped graphitic carbon nitride as Z-scheme photocatalyst for efficient photodegradation of 2,4-dinitrophenol. J. Environ. Chem. Eng. 2019, 7, 103272. [CrossRef]

22. Sudhaik, A.; Raizada, P.; Thakur, S.; Saini, R.V.; Saini, A.K.; Singh, P.; Thakur, V.K.; Nguyen, V.-H.; Khan, A.A.P.; Asiri, A.M. Synergistic photocatalytic mitigation of imidacloprid pesticide and antibacterial activity using carbon nanotube decorated phosphorus doped graphitic carbon nitride photocatalyst. J. Taiwan Inst. Chem. Eng. 2020, 113, 142-154. [CrossRef]

23. Mills, A.; Le Hunte, S. An overview of semiconductor photocatalysis. J. Photochem. Photobiol. A Chem. 1997, 108, 1-35. [CrossRef]

24. Widegren, J.A.; Finke, R.G. A review of the problem of distinguishing true homogeneous catalysis from soluble or other metal-particle heterogeneous catalysis under reducing conditions. J. Mol. Catal. A Chem. 2003, 198, 317-341. [CrossRef]

25. Belver, C.; Bedia, J.; Gómez-Avilés, A.; Peñas-Garzón, M.; Rodriguez, J.J. Semiconductor Photocatalysis for Water Purification. In Nanoscale Materials in Water Purification; Elsevier: Amsterdam, The Netherlands, 2019; pp. 581-651.

26. Zhang, F.; Wang, X.; Liu, H.; Liu, C.; Wan, Y.; Long, Y.; Cai, Z. Recent advances and applications of semiconductor photocatalytic technology. Appl. Sci. 2019, 9, 2489. [CrossRef]

27. Zhang, L.; Ran, J.; Qiao, S.-Z.; Jaroniec, M. Characterization of semiconductor photocatalysts. Chem. Soc. Rev. 2019, 48, 5184-5206. [CrossRef] [PubMed]

28. $\mathrm{Xu}, \mathrm{Y}$;; Schoonen, M.A. The absolute energy positions of conduction and valence bands of selected semiconducting minerals. Am. Mineral. 2000, 85, 543-556. [CrossRef]

29. Hayat, A.; Taha, T.A.; Alenad, A.M.; Ullah, I.; Shah, S.; Uddin, I.; Ullah, I.; Hayat, A.; Khan, W.U. A simplistic molecular agglomeration of carbon nitride for optimized photocatalytic performance. Surf. Interfaces 2021, 25, 101166. [CrossRef]

30. Hayat, A.; Sohail, M.; Taha, T.A.; Alenad, A.M.; Uddin, I.; Hayat, A.; Ali, T.; Shah, R.; Irfan, A.; Khan, W.U.; et al. A Superficial Intramolecular Alignment of Carbon Nitride through Conjugated Monomer for Optimized Photocatalytic $\mathrm{CO}_{2}$ Reduction. Catalysts 2021, 11, 935. [CrossRef]

31. Raziq, F.; Hayat, A.; Humayun, M.; Mane, S.; Liang, Q. Photocatalytic solar fuel production and environmental remediation through experimental and DFT based research on CdSe-QDs-coupled P-doped-g- $\mathrm{C}_{3} \mathrm{~N}_{4}$ composites. Appl. Catal. B Environ. 2020, 270, 118867. [CrossRef]

32. Hayat, A.; Alrowaili, Z.A.; Taha, T.A.; Khan, J.; Khan, W.U. Organic heterostructure modified carbon nitride as apprehension for Quercetin Biosensor. Synth. Met. 2021. [CrossRef]

33. Hayat, A.; Raziq, F.; Khan, M.; Khan, J.; Khan, W.U. Fusion of conjugated bicyclic co-polymer within polymeric carbon nitride for high photocatalytic performance. J. Colloid Interface Sci. 2019, 554, 627-639. [CrossRef] [PubMed]

34. Hayat, A.; Raziq, F.; Khan, M.; Ullah, I.; Khan, W.U. Visible-light enhanced photocatalytic performance of Polypyrrole/g-C $\mathrm{C}_{3} \mathrm{~N}_{4}$ composites for water splitting to evolve $\mathrm{H}_{2}$ and pollutants degradation. J. Photochem. Photobiol. A Chem. 2019, 379, 88-98. [CrossRef]

35. Huang, C.; Wen, Y.; Ma, J.; Dong, D.; Zhang, Y. Unraveling fundamental active units in carbon nitride for photocatalytic oxidation reactions. Nat. Commun. 2021, 12, 320. [CrossRef]

36. Hayat, A.; Taha, T.A.; Alenad, A.M.; Ali, T.; Bashir, T.; Rehman, A.U.; Ullah, I.; Hayat, A.; Irfan, A.; Khan, W.U. A molecular amalgamation of carbon nitride polymer as emphasized photocatalytic performance. Int. J. Energy Res. 2021, 45, 19921-19928. [CrossRef]

37. Ullah, A.; Khan, J.; Sohail, M.; Hayat, A.; Khan, W.U. Fabrication of Polymer Carbon Nitride with Organic Monomer for Effective Photocatalytic Hydrogen Evolution. J. Photochem. Photobiol. A Chem. 2020, 401, 112764. [CrossRef]

38. Khan, M.; Li, T.; Hayat, A.; Zada, A. A concise review on the elastomeric behavior of electroactive polymer materials. Int. J. Energy Res. 2021. [CrossRef] 
39. Ah, A.; Ns, B.; Iu, C.; Mk, D.; Skbmb, E.; Ah, F.; Iu, G.; Aur, H.; Ta, I.; Gm, J. Molecular engineering of carbon nitride towards photocatalytic $\mathrm{H}_{2}$ evolution and dye degradation. J. Colloid Interface Sci. 2021, 597, 39-47.

40. Xu, J.; Gao, J.; Chao, W.; Yu, Y.; Lei, W. NH 2 -MIL-125(Ti)/graphitic carbon nitride heterostructure decorated with NiPd co-catalysts for efficient photocatalytic hydrogen production. Appl. Catal. B Environ. 2017, 219, 101-108. [CrossRef]

41. Arif, N.; Uddin, I.; Hayat, A.; Khan, W.U.; Ullah, S.; Hussain, M. Homogeneous Iron-Doped Carbon Nitride-Based Organocatalysts for sensational photocatalytic performance under Visible Light-Driven. Polym. Int. 2021, 70, 1273-1281. [CrossRef]

42. Hayat, A.; Shaishta, N.; Mane, S.K.B.; Khan, J.; Hayat, A. Rational Ionothermal Copolymerization of TCNQ with PCN Semiconductor for Enhanced Photocatalytic Full Water Splitting. ACS Appl. Mater. Interfaces 2019, 11, 46756-46766. [CrossRef] [PubMed]

43. Rahman, M.U.; Hayat, A. Green synthesis, properties, and catalytic application of zeolite (P) in production of biofuels from bagasse. Int. J. Energy Res. 2019, 43, 4820-4827. [CrossRef]

44. Hayat, A.; Li, T. A facile supramolecular aggregation of trithiocyanuric acid with PCN for high photocatalytic hydrogen evolution from water splitting. Int. J. Energy Res. 2019, 43, 5479-5492. [CrossRef]

45. Nie, N.; Zhang, L.; Fu, J.; Cheng, B.; Yu, J. Self-assembled hierarchical direct Z-scheme g- $\mathrm{C}_{3} \mathrm{~N}_{4} / \mathrm{ZnO}$ microspheres with enhanced photocatalytic $\mathrm{CO}_{2}$ reduction performance. Appl. Surf. Sci. J. Devoted Prop. Interfaces Relat. Synth. Behav. Mater. 2018, 441, 12-22.

46. Zhu, W.; Ke, J.; Wang, S.B.; Ren, J.; Wang, H.H.; Zhou, Z.Y.; Si, R.; Zhang, Y.W.; Yan, C.H. Shaping Single-Crystalline Trimetallic Pt-Pd-Rh Nanocrystals toward High-Efficiency C-C Splitting of Ethanol in Conversion to CO $_{2}$. ACS Catal. 2015, 5, 1995-2008. [CrossRef]

47. Wang, Y.; Wang, X.; Antonietti, M. ChemInform Abstract: Polymeric Graphitic Carbon Nitride as a Heterogeneous Organocatalyst: From Photochemistry to Multipurpose Catalysis to Sustainable Chemistry. ChemInform 2012, 43. [CrossRef]

48. Lin, J.; Pan, Z.; Wang, X. Photochemical Reduction of $\mathrm{CO}_{2}$ by Graphitic Carbon Nitride Polymers. ACS Sustain. Chem. Eng. 2014 2, 353-358. [CrossRef]

49. Di, W.; Yang, J.; Zhang, Y.; Li, J.; Yu, Y.; Zhang, Y.; Zhu, Z.; Li, W.; Wu, C.; Luo, L. Device structure-dependent field-effect and photoresponse performances of p-type ZnTe:Sb nanoribbon. J. Mater. Chem. 2012, 22, 6206-6212.

50. Kibria, M.G.; Nguyen, H.; Cui, K.; Zhao, S.; Mi, Z. One-Step Overall Water Splitting under Visible Light Using Multiband InGaN/GaN Nanowire Heterostructures. ACS Nano 2013, 7, 7886-7893. [CrossRef] [PubMed]

51. Rehman, A.U.; Khan, M.; Zheng, M.; Khan, A.R.; Hayat, A. Thermochemical heat storage behavior of $\mathrm{ZnSO}_{4} \cdot 7 \mathrm{H}_{2} \mathrm{O}$ under low-temperature. Heat Mass Transf. 2020, 57, 765-775. [CrossRef]

52. Nickel Oxide Nano-Particles on 3D Nickel Foam Substrate as a Non-Enzymatic Glucose Sensor. J. Electrochem. Soc. 2019, 166, B1602-B1611. [CrossRef]

53. Rehman, A.U.; Shah, M.Z.; Zhao, T.; Shah, R.; Zheng, M. Thermochemical heat storage ability of $\mathrm{ZnSO}_{4} \cdot 7 \mathrm{H}_{2} \mathrm{O}$ as potential long-term heat storage material. Int. J. Energy Res. 2020, 45, 4746-4754. [CrossRef]

54. Shaishta, N.; Khan, W.U.; Mane, S.; Hayat, A.; Manjunatha, G. Red-emitting $\mathrm{CaSc}_{2} \mathrm{O}_{4}: \mathrm{Eu}^{3+}$ phosphor for NUV-based warm white LEDs: Structural elucidation and Hirshfeld surface analysis. Int. J. Energy Res. 2020. [CrossRef]

55. Uddin, I.; Wang, G.; Gao, D.; Hussain, Z.; Hayat, A. Conventional and cement-catalyzed co-pyrolysis of rice straw and waste polyethylene into liquid and gaseous fuels by using a fixed bed reactor. Biomass-Convers. Biorefinery 2021, 1-10. [CrossRef]

56. Jia, R.; Zhang, Y.; Yang, X. High efficiency photocatalytic $\mathrm{CO}_{2}$ reduction realized by $\mathrm{Ca}^{2+}$ and HDMP group Co-modified graphitic carbon nitride. Int. J. Hydrog. Energy 2021, 46, 32893-32903. [CrossRef]

57. Fang, Y.; Fu, X.; Wang, X. Diverse polymeric carbon nitride-based semiconductors for photocatalysis and variations. ACS Mater. Lett. 2020, 2, 975-980. [CrossRef]

58. Sohail, M.; Xue, H.; Jiao, Q.; Li, H.; Khan, K.; Wang, S.; Feng, C.; Zhao, Y. Synthesis of well-dispersed $\mathrm{TiO}_{2} / \mathrm{CNTs} @ C o F e_{2} \mathrm{O}_{4}$ nanocomposites and their photocatalytic properties. Mater. Res. Bull. 2018, 101, 83-89. [CrossRef] 